\title{
AMYLOIDOSIS IN PARAPLEGIA
}

\author{
By Dr. A. Maglio and Dr. P. Potenza \\ Centro Paraplegici INAIL, Lido di Roma, Italy.
}

\section{FOREWORD}

THE majority of investigators have so far considered amyloidosis as a secondary disease, which follows a wide variety of chronic processes (syphilis, tuberculosis, osteomyelitis, etc.).

In the past century, however, some cases were reported in which no previous disease was found. (Wild, I886; Nowak, I898, and others).

This and other considerations stimulated an attempt at a proper classification of this disease and an analysis of its primary or secondary character, its extent and its morphological aspects.

Since the classification published by Strauss (1933) just thirty years ago, about a dozen classifications have appeared in world literature. However, attempts to give an accurate and complete description of the disease, based on morphogenetic, morphologic, clinical, or biochemical aspects, have not been conclusive and even the best classifications are incomplete and contradictory.

The succession of classifications just proves the badly felt need for a clarification and systematisation of this problem in all its aspects. In our view, all the classifications are wanting, because they lack a sound aetiological and pathogenetic basis.

(A) Primary Amyloidosis. Atypical amyloidosis, after about 50 years of obscurity, was revived by Lubarsch in I929. He found five cases in the literature and added three of his own; he listed the five main characteristics of primary amyloidosis as follows:

I. The organs and tissues which are severely involved in secondary amyloidosis (spleen, kidneys, adrenals, liver, intestinal mucosa, salivary glands) are almost completely spared.

2. The organs which are spared or eventually involved to a small degree in secondary amyloidosis (heart, lungs, smooth and striated muscles, skin, serous membranes, etc.) are selectively affected in primary amyloidosis.

3. Frequent occurrence of small or large lumps of the amyloid substance.

4. Frequent occurrence of irregular dye reactions.

5. Absence of a demonstrable primary disease.

Since Lubarsch's publication the number of reports have increased steadily and have become more and more accurate. Holetsky and Stecher (1939) report 34 cases, Eisen (I946) 48 cases, Higgins and Higgins (I950) 7I cases, Gianni (I952) 75 cases, Mathews (1954) 88 cases and Symmers (1956) I 50 cases.

Symmers points out that in his report there are no cases of senile amyloidosis although many of them have appeared elsewhere in the literature.

(B) Secondary Amyloidosis. Secondary amyloidosis undoubtedly forms the most frequent group, and it follows a great number of diseases, mainly of the 
chronic inflammatory or neoplastic type. Of the inflammatory type the most frequent is still pulmonary tuberculosis. A considerable number may also be connected with rheumatoid arthritis. Of other chronic inflammatory diseases which may lead to amyloidosis, we should mention kala-azar, leprosy and a disease called 'Maladie périodique', F.M.F. (familial mediterranean fever, etc., which is characterised by fever, arthropathies, joint and thoraco-abdominal pains). Generalised, especially renal amyloidosis is rather frequent, although no precise data on its frequency are as yet available (Reimann \& Angelides, I95I; Mamou \& Cattan, 1952; Heller et al., I958).

The diagnosis of secondary amyloidosis is based on the history of a previous disease rather than on histological changes or their specific distribution.

An active disease, or one that has been found in the patient's history, cannot always be easily interpreted as a cause-effect relationship, and the assumption of a relationship depends entirely on the judgment of the observer.

Eisen (1946) found in his first reported case that amyloidosis was associated with an eosinophilic adenoma. This case was considered as one of primary amyloidosis and the association a fortuitous one. A case of amyloidosis associated with rheumatic fever was considered a primary one by Dillon and Evans (1942); Bero (1957) reached the same conclusion in a case of amyloidosis in a patient suffering from multiple sclerosis.

In more complicated cases, however, the relationship may be even more obscure. An example is another case reported by Bero of a patient with Hodgkin's disease complicated by an empyema and treated with nitrogen mustard and X-rays. In this case, every one of the four factors involved, and not the Hodgkin's disease alone, may have provoked the amyloidosis.

In recent years amyloid disease in spinal paraplegia has been a subject of publications (Bowman and Redfield, I95 I; Newman \& Jacobsen, I953; Moses, I954; Comarr, I954; Tribe, I963). Two cases have come under our observation and are presented in this paper.

Case I. D. S., age 44. Family and personal history were non-contributory.

At the age of 33, following an accident at work, he sustained a traumatic lesion of the spinal cord at the level of TIO with paralysis of both lower limbs, loss of sensation and loss of sphincter control. A plaster corset was applied in the hospital where he was first treated, but it had to be removed 40 days later on account of many decubitus ulcers. For about one year the patient carried an indwelling Nelaton catheter permanently connected to gravity drainage. This was removed, as automatic voiding reappeared, without a cystometric evaluation.

The patient states that since then he voided every two hours about $100 \mathrm{cc}$. of cloudy, fetid urine, which has occasionally been purulent.

Decubitus ulcers affected the sacro-iliac, scapular, trocanteric and calcaneal regions: they eventually healed four years later.

About I 8 months after accident the patient was discharged from hospital and returned to his home, for family reasons. At that time he began to suffer from'intermittent febrile episodes every one to two months, lasting nine to ten days. The local physician diagnosed 'urinary fevers' and advised hospitalisation, which the patient constantly refused.

At the age of 42 these febrile episodes became more frequent (two or three per month), and there occurred some oedema of the legs, as well as oliguria and a decubitus ulcer over the sacrum.

At the age of 43 he was admitted to our Centre for treatment. On examination. 
his general condition was found to be poor; he had hypertension (170/100), with an ECG showing signs of myocardial damage, and pitting oedema of the lower limbs. Over the sacro-iliac region there was a large crater-like decubitus ulcer of 12 by $16 \mathrm{~cm}$. in diameter and roughly oval in shape, with a torpid, secreting base (X-rays of the underlying bone failed to reveal any osteitic change). Both the liver and the spleen were enlarged.

On manual palpation, both kidney poles were found to be markedly increased in volume. Giordano's sign was positive. Urine, which was excreted at the rate of $600 \mathrm{cc}$. per day, was very cloudy with a large amount of grossly purulent sediment.

Blood urea nitrogen: 0.70 per cent. Urea clearance $\mathrm{Cm}=25$ per cent. I.V.P. performed when B.U.N. was down to 0.42 per cent., showed a marked bilateral hydronephrosis. Cystogram showed bilateral ureteric reflux. Chromocystoscopy showed delay on both sides in the excretion of the dye.

The diagnosis, therefore, was: bilateral hydro-pyonephrosis and renal deficiency. Eight months after admission to our Centre the patient died.

Case 2. A.C., aged 38. Family and personal history were non-contributory.

At the age of 24, following injury at work, he sustained a traumatic lesion of the spinal cord at the level of TI2 with paraplegia and loss of sphincter control. From the time of the accident to the time of admission to our Centre eight months before his death the patient suffered from a large right ischial fistula with osteomyelitis of the ischial tuberosity.

For the last eight years the patient had never been hospitalised and had suffered from several febrile episodes (one about every two months) accompanied by pyuria and bilateral sacral pain.

At the age of 34 the patient had several acute attacks of bronchopneumonia, especially during the winter months.

At the age of 37 cystopyelitic episodes became more frequent (two per month) so that patient decided to accept admission to our Centre.

On examination, his general condition was found to be very poor; blood pressure was within normal limits, except for occasional hypertensive crises, up to $180 \mathrm{~mm}$. $\mathrm{Hg}$. ECG showed signs of myocardial damage. X-rays confirmed the presence of chronic bronchitis.

Palpation of the abdomen revealed marked enlargement of both spleen and liver. I.V.P. showed a marked bilateral hydronephrosis, but a cystogram showed no ureteric reflux. Chromocystoscopy revealed some delay in the excretion of indigo-carmine.

Urine: 700 cc. per 24 hours; bladder capacity: $300 \mathrm{cc}$. Residual urine: $210 \mathrm{cc}$. B.U.N. $=0.44$ per cent. Urea clearance $\mathrm{Cm}=30$ per cent. Marked anaemia and high leukocyte count.

Large trochanteric decubitus ulcers were also present; they were crater-like, with a torpid base. The fistula over the right ischial region measured, at the skin level, 4 by $4 \mathrm{~cm}$. and penetrated into the ischial tuberosity, which on examination appeared markedly eroded with large osteolytic areas and much sero-purulent discharge. X-rays of the pelvis showed a large area of chronic osteomyelitis of the ischial bone in the region of the tuberosity.

The general condition of the patient, already poor on his admission, became gradually worse, until he died of renal deficiency.

All autopsy material was submitted for histological examination by the usual methods and for histochemical tests to evaluate the presence and the extent of amyloidosis.

To avoid needless duplication, we shall describe the histology of the involved organs of both cases. 


\section{HISTOLOGY}

Liver. The hepatic lobular structure was to a greater or lesser degree altered by the presence of disorderly trabecular masses of an amorphous eosinophylic substance. Amongst the trabeculae one could sometimes recognise rows of hepatic cells with varying degrees of atrophy.

The amorphous material present within the hepatic parenchyma involved 60 to 80 per cent. of all structures. The peri-portal hepatocytes were generally more numerous and better preserved. The collagenic and reticular stroma was increased, but only moderately so.

Amyloid stained with Congo-red became a bright orange, of a consistent graduation in all cases; with Van Gieson a yellow-brown and with Azan-Mallory various graduations of blue, sometimes with pinkish hues, particularly around the vessels.

Spleen. The two cases showed a different extension of the amyloid substance in the follicles.

In one of them, amyloid was limited to arterioles and to the larger arteries in the follicular and para-follicular area. In the other the follicles were more or less massively involved.

The peri-follicular masses extended both centrifugally towards the pulp and centripetally towards the centre of the follicle; in certain areas the masses were separated by a granulomatous reaction with innumerable giant foreign body cells, which sometimes contained amyloid fragments in their cytoplasm. Congo-red, Van Gieson and Azan-Mallory stained the amyloid in their respective typical colours.

Kidneys. Renal amyloid involved the glomeruli, the arterioles and the pericanalicular areas, especially in the medullary portion. Glomeruli appeared mostly larger, with much eosinophylic amorphous material in the capillary wall. In the narrowed lumen one might occasionally recognise some red blood cells. Bowman capsule was reduced or was totally absent as a result of the adhesion or fusion of the glomerular loops with the capsular wall. The larger arteries of the cortex were not invariably affected.

Amyloid was present in the medullary portion, affecting both the blood vessels (often the walls were completely replaced) and the peri-canalicular areas. A marked degree of nephrosis, often of the osmotic (hydropic and vacuolar) and sometimes of the hyaline type, was frequently associated. Few red blood cells fragments were infrequently seen in the tubules.

Adrenal Glands. In the adrenal glands, amyloid was rather diffuse, although it always spared the medulla and part of the glomerular portion. More severely involved was the fasciculate portion with atrophy and disappearance of rows of cells. The reticular portion was also involved and there was also amyloid in the vessels.

\section{HISTOCHEMICAL METHODS}

Van Gieson. This staining method gave to all the specimens a brownishyellow or yellow-orange colour. Great importance has been attributed in the literature to this reaction which was interpreted as the exclusive result of picric acid in the staining solution. Testing separately the sections with picric acid and with 
fuchsine, the necessity for the presence of both substances to obtain the above results has been demonstrated.

Azan-Mallory. This method has given various graduations between pale blue and red.

$P A S$. With all methods the presence of glycol groups has been demonstrated. Intensity variations were the same as those described by Hale.

The constantly negative reaction after acetilation and its reappearance after saponification seemed to confirm that the substance was of a polysaccharic nature.

The slight weakening of the periodic-acid-Schiff reaction after treatment with diastases showed how small was the amount of simple polysaccharides contained in the material.

These findings seem to demonstrate the presence of a large quantity of glycoprotein compounds, particularly those containing dicarboxilic amino acids (such as the aspartic and the glutamic), and the relative shortage of the ones containing arginine and lysine.

Alcian-Chlorantin. This method shows a high mucopolysaccharic acids content.

The Hale method gives approximately the same results.

Methylation, carried out at different times and temperatures, has constantly caused a complete disappearance of positivity, which reappeared, in a weaker degree than in the controls, after saponification. Such results indicate the presence of associated mucopolysaccharides, both with and perhaps more commonly without sulphur, which would be revealed by the double treatment. It may be noted that Lison (I960) does not consider these reactions as absolutely specific.

The little or absent effect of testicular hyaluronidase seems to indicate the presence, among various types of acid mucopolysaccharides, of B-chondroitinsulphate and/or heparin (heparinlike substance).

\section{DISCUSSION}

In the two cases presented primary amyloidosis can be ruled out. Moreover, the past history of the patients did not reveal diseases such as tuberculosis, rheumatic disease, myeloma, Hodgkin's disease, or neoplasm as aetiological factors in the development of the amyloid disease in our cases. In analysing the relationship between paraplegia and amyloidosis there can hardly be any doubt that the chronic suppurative infections resulting in severe disturbance of the protein metabolism are responsible for the development of amyloidosis in our patients. Both patients were suffering from long-standing pressure sores (in the second case the underlying osteomyelitis could be diagnosed) and infection of the urinary tract; and in agreement with previous authors we believe that the combination of pressure sores and chronic infection of the urinary tract is the underlying aetiology of amyloidosis in spinal paraplegia. Recently Tribe (1963) found that in some cases renal suppuration by itself may lead to amyloidosis. Further observations will be necessary to show in what percentage and in what type of renal affliction in spinal paraplegia this occurs.

\section{SUMMARY}

A short survey is given on the classifications of primary and secondary amyloidosis. 
Two cases of amyloidosis in traumatic paraplegic patients are presented and clinical symptoms as well as the post-mortem histological and histochemical findings in various organs are described.

The causative relationship between the complications following paraplegia pressure sores and infection of the urinary tract and amyloidosis is discussed.

\section{RÉSUMÉ}

Un aperçu sur la classification des amyloses primaires et secondaires est donné.

Deux cas de paraplègie traumatique avec amylose sont présentés, comprenant l'evolution clinique ainsi que les résultats d'autopsie portant sur l'aspect histologique et histochimique des différents organes.

La relation probable entre les complications de la paraplègie, escharres et infections urinaires, avec l'amylose, est discutée.

\section{ZUSAMMENFASSUNG}

Nach einer kurzen Uebersicht ueber die Einteilungsversuche von primaerer und sekundaerer Amyloidose werden zwei Faelle von Amyloidose bei traumatischen Paraplegikern, ihre klinischen Symptome und die histologischen und histochemischen Sektionsbefunde beschrieben.

Die Verfasser diskutieren die Kausalzusammenhaenge zwischen den Komplikationen der Querschnittslaehmung, Dekubiti und Infektion der Harnwege einerseits und der Amyloidose andrerseits.

\section{REFERENCES}

BowmAN, M., \& REDFIELD, E. (I95I). U.S. armed Forces med. F., 2, 715.

Bero, G. L. (I957). Ann. intern. Med., 46, 93 I.

Comarr, A. E. (I954). Proc. 3rd Clin. Paraplegia Conf., p. I8. Vet. Admin. U.S.A.

Dillon, J. A., \& Evans, L. (I942). Ann. intern. Med., I7, 722.

Eisen, H. N. (1946). Amer. F. Med., I, I44.

GIANNI, A. (I952). La morfologia della malattia amiloide. In: Fisiopatologia e clinica del proditoplasma di E; Poli. Milano: Delfino Soc.

Heller, H., Sohar, E., \& Sherf, L. (1958). Arch. intern. Med., I02, 50.

Higgins, W. H., \& Higgins, W. H., jr. (I950). f. med. Sci., 220, 6 Io.

Holetsky, S., \& Stecher, R. M. (1939). Arch. Path., 27, 267.

LIson, L. (I960). Histochimie et Cytochimie animales. Paris: Gauthier-Villar.

LubarsCh, O. (1929). Virchows Arch. path. Anat., 27I, 867.

Mamou, H., \& Cattan, R. (I952). Sem. Hôp. (Paris), 28, 1062.

Mathews, W. H. (I954). Amer. F. med. Sci., 228, 317.

Moses, D. S. (I954). Proc. 3rd Clin. Paraplegia Conf., p. I4. Vet. Admin. U.S.A.

NewMan, W., \& JACOBSEN, A. S. (1953). Amer. F. med., 15, 216.

Nowak, J. (1898). Virchows Arch. path. Anat., 152, I6I.

Reimann, H. A., \& Angelides, A. P. (I95I). F. Amer. med. Ass., 146, 713.

Strauss, A. (1933). Virchows Arch. path. Anat., 291, 2 I9.

Symmers, W. ST. C. (1956). F. clin. Path., 9, I87.

Tribe, C. R. (1963). Int. F. Paraplegia, I, 7I.

WILD, C. (I886). Beitr. pash. Anat., I, I77. 